\title{
O pluralismo axiológico do "jovem Canguilhem” no contexto da ascensão do fascismo (1926-1939)
}

\author{
Caio Souto ${ }^{1}$
}

Resumo: Os textos publicados por Georges Canguilhem durante as décadas de 1920-1930, que desenvolviam uma filosofia dos valores com certa inflexão política, receberam grande influência do neokantiano Alain (pseudônimo de Émile Chartier). O grupo dos intelectuais reunidos em torno de Alain militava em favor do pacifismo, visando evitar um novo conflito mundial. Contudo, a ascensão do fascismo provocou uma nova postura por parte do "jovem Canguilhem", que publicou anonimamente os resultados de uma pesquisa empírica com o título "Le fascisme et les paysans", levando sua filosofia axiológica de então a uma nova inflexão política, culminando numa ruptura com o pensamento de Alain e de seu grupo.

Palavras-chave: Canguilhem - filosofia política - Auguste Comte - Alain

\section{The "young Canguilhem"'s axiological pluralism in the context of the rise of} fascism (1926-1939)

\begin{abstract}
The texts published by Georges Canguilhem during the 1920-1930s, which developed a philosophy of values with a certain political inflection, received the influence from the neo-Kantian Alain (pseudonym of Émile Chartier). The group of intellectuals gathered around Alain was campaigning for pacifism, aiming to avoid a new world conflict. However, the rise of fascism provoked a new stance on the part of the "young Canguilhem", that published anonymously the results of his empirical research intitled "Le fascisme et les paysans", taking his axiological philosophy to a new political inflection, culminating in a break with the thinking of Alain and his group.
\end{abstract}

Keywords: Canguilhem - political philosophy - Auguste Comte - Alain

1 Doutor em Filosofia e professor de Filosofia do Instituto Federal do Amazonas (IFAM). E-mail: caiosouto@gmail.com 


\section{O problema da Revolução ${ }^{2}$}

Quem fizer a história da recepção do pensamento de Georges Canguilhem, dentro e fora da França, deverá notar algumas datas importantes, que não correspondem exatamente às de suas publicações originais. O leitor anglófono, por exemplo, só pôde conhecer a tradução de Le normal et le pathologique em 1978, quando surgiu a edição prefaciada por Foucault. E teve de esperar até o ano de 1994 para ter acesso a um volume que compilasse alguns de seus outros escritos mais importantes ${ }^{3}$. Foi então que o grande público pôde descobrir, a partir de uma extensa "Critical Bibliography" realizada por Camille Limoges", que Canguilhem havia escrito mais de uma centena de textos anteriores à sua célebre tese em medicina, de 1943, que ficaria conhecida por seu título simplificado Le normal et le pathologique. Trata-se de textos em periódicos como Libres propos 5 , Europe e Méthode $e^{7}$, além do opúsculo político publicado anonimamente Le fascisme et les paysans (1935), junto ao "Comité de Vigilance des Intellectuels Antifascistes" (CVIA), e um tratado escolar em coautoria com Camille Planet, o Traité de logique et de morale (1939). Não tardou a aparecer a primeira análise referente a tais textos, creditando-se a J.-F. Braunstein ${ }^{8}$ o pioneirismo. Mais recentemente, contemporâneo ao surgimento do primeiro tomo das obras completas de Canguilhem, publicado em 2011, surgiu também a primeira tese inteiramente dedicada ao "jovem Canguilhem"'.

Faremos notar neste artigo, utilizando-nos dos já mencionados comentários, que desde essa época o autor oferecia, de modo original, soluções aos problemas filosóficos que se propôs enfrentar. Desde o início, tendo herdado de Alain e da Wertphilosophie uma filosofia axiológica, ele a pratica segundo um estilo cujo traço não se deixará apagar mesmo em seus últimos textos. Contudo, o acontecimento político da ascensão do fascismo e a iminência da guerra contribuíram decisivamente para que ele se afastasse de Alain e fosse conduzido a domínios estranhos à filosofia. Tal decisão resultará na formulação de uma "fillosofia dos valores" original, não podendo, pois, ser deduzida apenas das condições materiais que a tornaram possível. E se é possível observar mutações entre sua "filosofia de juventude" e as demais que em seguida poderemos encontrar em sua obra, tais reformulações correspondem

\footnotetext{
${ }^{2}$ Este artigo reformula algumas passagens de minha tese de doutorado em filosofia defendida pela UFSCar sob a orientação de Thelma Lessa da Fonseca no ano de 2019 que teve o título Georges Canguilhem: o devir de um pensamento. A pesquisa contou com financiamento da CAPES.

3 Trata-se da edição organizada por François Delaporte, que fez a seleção dos textos e os submeteu a uma tradução, que foi prefaciada por Paul Rabinow: Cf. DELAPORTE, François (ed.). A vital rationalist: selected writings from Georges Canguilhem. Alguns dos textos escolhidos por Delaporte eram notas de curso inéditas, publicadas então com a autorização de Canguilhem, as quais foram republicadas nas obras completas. As demais notas de curso e outros textos que Canguilhem não publicou em vida, e que não serão mais publicados, estão hoje disponíveis no CAPHÉS-ENS.

${ }^{4}$ LIMOGES, "Critical bibliography”. In: DELAPORTE, François (ed.) A vital rationalist: selected writings from Georges Canguilhem, pp. 385-454.

5 A revista Libres propos foi fundada por Alain em 1921 e Canguilhem assumiria a sua redação em 1932, tendo nela publicado mais de trinta pequenos textos, alguns deles - os mais combativos - sob o pseudônimo de C.G. Bernard.

${ }^{6}$ Canguilhem colaborou para esta revista entre 1929 a 1936, com artigos menos políticos, menos polêmicos e mais filosóficos (a revista será interrompida entre 1939 e 1946, sendo depois inteiramente controlada pelo PCF).

7 Pequeno periódico que teve apenas 6 números publicados.

${ }^{8}$ BRAUNSTEIN, "Canguilhem avant Canguilhem".

${ }^{9}$ ROTH, Georges Canguilhem et l'école française de l'activité. Acompanhamos a designação de "jovem Canguilhem" o autor dos textos referentes ao período compreendido entre 1926 e 1939.
} 
melhor a uma reabertura de problemas $^{10}$ do que ao desenvolvimento de questões já em germe desde o início.

\section{Auguste Comte: uma filosofia do Amor}

Canguilhem manifestou logo cedo uma preocupação com as relações entre saber e política. Sua monografia de conclusão de curso na École Normale Supérieure, defendida em 1926 sob a orientação do sociólogo Célestin Bouglé, intitulado La théorie de l'ordre et du progrès chez Comte ${ }^{11}$, analisava na obra de Comte o conceito de progresso social em sua relação com o conceito de ordem. Muitas das considerações avançadas em $\mathrm{O}$ normal e o patológico no capítulo sobre Comte aparecem embrionariamente aqui, onde Canguilhem não elabora ainda uma crítica ao positivismo, mas busca apreender o seu sentido lógico e coerente, uma coerência entre o pensamento da ordem (equilíbrio, estabilidade) e o do progresso (movimento, instabilidade). Esse memorial se inicia propondo uma distinção entre ordem social e ordem sociológica. A primeira possui um sentido vasto, como o de um comando ou de uma ordem jurídica, por exemplo. Já a segunda, trata-se da ordem em sentido estrito, isto é, o conjunto das relações "enquanto submetidas, não mais às vontades individuais, mas à condição necessária de toda atividade humana" ${ }^{2}$. É esta última que pode ser objeto de uma ciência nova que Comte proporá fundar, a sociologia. A identificação e a análise da ordem sociológica são consideradas essenciais para que a humanidade possa dirigir-se a um progresso, que nada mais é do que o desenvolvimento de uma ordem oculta nas relações sociais que a ciência deverá desvelar através de um método a ser constituído e que o positivismo proporá constituir. Sendo esse novo objeto (a ordem sociológica) irredutível a todos os demais, essa nova ciência a ser criada será uma ciência igualmente irredutível a todas as outras. Mais que isso, ela deve ser a última das ciências.

Desse modo, Comte considerará como implícitas no conceito de progresso as leis fundamentais da evolução humana, que ele proporá analisar a partir de sua história. Se, por um lado, ordem e progresso se encontram indissoluvelmente ligados no positivismo, por outro, o conhecimento da ordem possui uma anterioridade lógica, devendo ser conhecido primeiramente, por uma "precaução de método". Contudo, embora reconhecesse que a noção de ordem já tivesse sido bem elaborada desde a Antiguidade por Aristóteles, ainda não se trataria da ordem sociológica, e é sobre esta última que o positivismo deverá se dedicar. Quanto à noção de progresso social, apenas com os iluministas, como Condorcet, é que ela passou a adquirir uma conceituação filosófica, e neste ponto Comte reconhecia o positivismo como continuador do projeto iluminista. Mas irá além de Condorcet, pois unirá dois aspectos principiais referentes à teoria da ordem e do progresso, introduzindo uma dimensão valorativa ao progresso que antes era concebido em termos apenas de fato: "a expressão de um duplo juízo", como distingue Canguilhem, "de um juízo de fato e de um juízo de valor, ambos estando aliás sempre unidos e sendo estreitamente dependentes"13.

\footnotetext{
10 Pensamos na definição de Léon Brunschvicg que Canguilhem certa vez adotou como sua: "A filosofia é a ciência dos problemas resolvidos" (apud CANGUILHEM, Le normal et le pathologique, p. 9); por conseguinte, interpretava Canguilhem, as reflexões filosóficas originais equivalem à reabertura dos problemas.

$11 \mathrm{O}$ manuscrito dessa monografia inédita se encontra disponível no CAPHÉS sob a cota GC. 6.1.

${ }^{12}$ CANGUILHEM, Théorie de l'ordre et du progrès chez Comte. CAPHÉS: GC. 6.1, fl. 6-7.

${ }^{13}$ CANGUILHEM, Théorie de l'ordre et du progrès chez Comte. CAPHÉS: GC. 6.1, fl. 18.
} 
Outra herança iluminista do positivismo, esta que será comentada por Canguilhem ao longo de toda a sua obra, reside em ter fundado o conhecimento dessa ordem que comanda o progresso a uma lei estática, por sua vez herdada dos estudos da física, especialmente da mecânica. Com efeito, é na primeira lei da termodinâmica, a lei de conservação de energia, que tanto Comte quanto Condorcet radicam o princípio da ordem que estaria implícita também no progresso social. Assim, como pressuposto metodológico, seria necessário conhecer antes as próprias leis físicas, antes de conhecer aquelas da dinâmica social que a ela se reportariam. Na tentativa de compreensão da luta constante entre a vida orgânica e o mundo físico inorgânico, Comte acabaria por ceder às leis que regem este último: "Quando passamos do inorgânico ao orgânico", observava Canguilhem já nesta monografia, "essa lei enuncia a subordinação das leis do movimento às leis da existência. Sociologicamente, essa lei é a lei da ordem e do progresso"14. Deste modo, não é inicialmente da biologia que Comte retira o modelo para a formulação de sua ciência social. Ele recua para muito antes, não abrindo mão de uma certa "lei da continuidade" entre o vivente e o não-vivente, entre o orgânico e o inorgânico. Assim, sua concepção da passagem da ordem ao progresso não deriva da compreensão acerca da especificidade do vivente. É, antes, ao "princípio de d'Alembert" ${ }^{15}$ que Comte busca a lei geral a partir da qual derivará sua sociologia. Portanto, sua base não sendo de início a biologia, é a partir da matemática (e na física newtoniana, que tem por modelo a matemática, e na qual se apoia o "princípio de d'Alembert') que ele estabelece a base do positivismo. E é, antes de tudo, na astronomia que Comte encontra a ordem fundamental da qual deriva a ordem social (e todas as demais ordens): uma ordem natural como condição da ordem social. Diz Canguilhem:

A relação da sociologia à astronomia é dupla. É uma relação de método e uma relação de fato. Uma relação de método porque a sociologia deve à astronomia, como todas as outras ciências, a ideia de ordem. Uma relação de fato porque a estabilidade astronômica envolve [entraîne] a estabilidade social $^{16}$.

Nesta chave, a produção humana passa a ser compreendida como inteiramente dependente da ordem astronômica. E é na lição 40ª do Cours de philosophie positive (1830-1842), primeira das duas grandes obras sistemáticas de Comte, que se estabelece a relação ascendente entre a ordem astronômica, a biológica e a sociológica, sendo que a astronomia é quem fornece as leis primeiras da estabilidade. Contudo, é apenas com a sociologia que o ciclo do conhecimento se fecha, pois - sempre segundo Comte - só pode haver conhecimento uma vez que há o ser humano. Assim, a ordem astronômica fornecendo a base para a compreensão científica do homem, é somente após esse conhecimento ter se voltado ao conhecimento do próprio homem (que é um ser vivente em determinado meio) que o próprio conhecimento encontra a si mesmo, ponto de apoio do qual ele não deve se

\footnotetext{
${ }^{14}$ CANGUILHEM, Théorie de l'ordre et du progrès chez Comte. CAPHÉS: GC. 6.1, fl. 21-22.

${ }^{15}$ D'Alembert estabeleceu um princípio para a mecânica que foi incorporado posteriormente. O "princípio de d'Alembert" pode ser enunciado assim: "o trabalho total realizado pelas forças efetivas é nulo em um deslocamento infinitesimal reversível, compatível com as ligações de qualquer sistema dinâmico" (LEECH, 1965, p.15).

${ }^{16}$ CANGUILHEM, Théorie de l'ordre et du progrès chez Comte. CAPHÉS: GC. 6.1, fl. 30.
} 
afastar. Aqui, Canguilhem retoma a afirmação de Bacon - "só se conhece a natureza obedecendo-a" - para explicar o pensamento da relação entre ordem e progresso em Comte: para progredir é preciso conhecer; o progresso é sucedâneo lógico e coerente da ordem. Logo, a coerência entre ordem e progresso impede que se pense um dos termos sem a pressuposição do outro. Eis, enfim, que esse ponto final é também o inicial, já que toda ciência é produção humana: "Da astronomia à sociologia, há um encadeamento de necessidades que tendem exatamente a mostrar o homem como estreitamente aprisionado num determinismo estrito e submetido a uma fatalidade insuperável"17.

Um pouco à frente, Canguilhem descreve a filiação de Comte ao princípio de continuidade entre normal e patológico estabelecido (o "princípio de Broussais", ao qual será dedicado o capítulo primeiro de Le normal et le pathologique), por sua vez uma derivação do "princípio de d'Alembert". E afirmará em seguida que, segundo Comte, a biologia é "que fornece um fundamento objetivo à possibilidade do progresso, isto é, à realidade de variações compatíveis com a ordem" ${ }^{18}$, uma vez reconhecido que a sociedade é um conjunto de seres viventes. É enquanto ser vivente, pois, que o homem se realiza enquanto ser social, havendo primeiro as necessidades materiais e de sobrevivência, primeiro os sentimentos; depois, num segundo momento, o pensamento; e, enfim, a ação objetivada. A esses três estágios é que correspondem justamente o estágio teológico (o dos sentimentos), o metafísico (o do pensamento) e o científico (o da ação objetivada).

As passagens entre tais estágios devem ocorrer progressivamente, estando o seu desenvolvimento já contido em crisálida desde o início. Compreender as relações humanas inerentes ao progresso como desenvolvimento da ordem implica, por exemplo, compreender o encadeamento entre o sentimento egoísta da primeira infância e o sentimento altruísta da fase adulta: "Os sentimentos altruístas devem nascer espontaneamente da ordem humana, não podem ser criados pelo cálculo" ${ }^{19}$. Não há, pois, uma teoria do indivíduo em Comte, mas tão somente uma teoria do social; apenas do social é que o social pode nascer, a primeira célula do social sendo a família (não o indivíduo). O amor de uma criança pela mãe, por exemplo, se traduz no amor pelo alimento e, portanto, a um amor de si; por sua vez, o amor de uma mãe pela criança se traduz no amor por uma parte de si mesma. E é desse laço que se inicia um sentimento de amor social, no seio da família: "Da biologia à sociologia, a passagem é assegurada pela família"20.

Assim, o positivismo não é um atomismo, já que coloca, na base das relações sociais, não o conjunto de indivíduos atomizados, mas as relações familiares que são anteriores aos próprios indivíduos (é da relação mãe-filho que surgem os indivíduos mãe e filho, os quais não existem previamente a essa relação): "Da família à Humanidade, há apenas um aprofundamento gradual da noção de sociedade" ${ }^{21}$. Canguilhem observa que essa concepção da relação entre ordem e progresso faz do positivismo, mais do que uma teoria, uma filosofia prática que tem por objetivo a reorganização social: restabelecer a ordem que permite o progresso. E Comte não se deu por satisfeito enquanto não viu seu trabalho culminar numa

${ }^{17}$ CANGUILHEM, Théorie de l'ordre et du progrès chez Comte. CAPHÉS: GC. 6.1, fl. 34.

${ }^{18}$ CANGUILHEM, Théorie de l'ordre et du progrès chez Comte. CAPHÉS: GC. 6.1, fl. 40.

${ }^{19}$ CANGUILHEM, Théorie de l'ordre et du progrès chez Comte. CAPHÉS: GC. 6.1, fl. 55.

${ }^{20}$ CANGUILHEM, Théorie de l'ordre et du progrès chez Comte. CAPHÉS: GC. 6.1, fl. 57.

${ }^{21}$ CANGUILHEM, Théorie de l'ordre et du progrès chez Comte. CAPHÉS: GC. 6.1, fl. 62. 
filosofia política, o que conduz à sua segunda grande obra, o Système de politique positive (18511854). Dela, Canguilhem dizia:

O Système de politique positive realiza o que previa o fim do Cours de philosophie positive: a subordinação de toda especulação, de toda abordagem teórica e prática, sob o ponto de vista humano. Aí está o segundo momento no desenvolvimento da doutrina. O primeiro momento foi uma síntese objetiva, ou um sistema enciclopédico de todas as doutrinas embasando, ao mesmo tempo, o mundo e o homem. A síntese subjetiva esclarece todos esses conhecimentos à luz da Humanidade e da moral. Pelo que, como vimos, o conhecimento das coisas nunca é um fim, já que o fim, o fim último que justifica todos os outros, é o valor da Humanidade e a salvação do homem. A filosofia deve ser uma moral. ${ }^{22}$

Eis que o sentimento básico a fundamentar todo esse progresso a ser conquistado pela humanidade na medida em que reconhece a si própria como a realização dos fins últimos estabelecidos desde o início por sua condição afetiva já contida nos laços familiares mais arcaicos é o Amor. Portanto, nesta monografia, em que já são trabalhadas muitas das questões com as quais viria a se defrontar com maior ou menor grau de reformulação em sua obra posterior, Canguilhem encontra o tema da construção social da paz entre os homens, a qual deveria ser fruto de uma prática política meticulosamente guiada por um saber científico. Além disso, é em Comte que ele encontra entrelaçadas a problemática moral e a social segundo uma perspectiva científica.

\section{O "pacifismo integral" 23 de Alain}

Durante a década de 1920, Canguilhem encontrava-se reunido, junto com diversos jovens estudantes da École Normale Supérieure, em torno da figura de Alain (pseudônimo de Émile Chartier). Com efeito, os temas estudados por Canguilhem em seu memorial sobre Comte são coerentes com a filosofia e com os interesses de seu tutor intelectual à época, que apreciava Célestin Bouglé (que dirigiu o memorial de conclusão de Canguilhem) como amigo e tinha um grande interesse pelo pensamento de Auguste Comte. A filosofia política de Alain, a exemplo da de Comte, fixava a fraternidade humana como um valor universal. Deplorando os resultados da Primeira Guerra Mundial, Alain pregava um pacifismo irrestrito, sobrepondo-o à iminência de uma nova guerra. Alain compreendia que esse pacifismo deveria ser compreendido como um ato de coragem derivado de um amor incondicional à Paz que a humanidade deveria construir conjuntamente ${ }^{24}$. Seus adeptos, dentre os quais

22 CANGUILHEM, Théorie de l'ordre et du progrès chez Comte. CAPHÉS: GC. 6.1, fl. 118. Canguilhem nunca deixará de insistir a respeito da diferença entre o Comte do Cours e o do Système. No entanto, ele não chega a reconhecer que, nesta segunda obra, a medicina já passa a ser vista como não podendo submeter-se à biologia, havendo uma "virada" com respeito à anterioridade da técnica médica sobre o conhecimento científico e biológico, este cada vez mais reduzido a um materialismo (Cf. BRAUNSTEIN, La philosophie de la médecine d'Auguste Comte: vaches carnivores, Vierge Mère et morts vivants).

${ }^{23}$ O termo "pacifismo integral" foi utilizado por Raymond Aron para se referir à postura política de Alain (Cf. ARON, "Réflexions sur le pacifisme integral").

${ }^{24}$ Tais ideias foram expostas, entre outras obras, sobretudo em: ALAIN, Mars on la guerre jugée, 1921. 
esteve Canguilhem durante toda a década de 1920, até meados dos anos 1930, militavam em manifestações e escreviam em periódicos por essa causa, o principal deles sendo os Libres Propos.

Como esclarece Giuseppe Bianco ${ }^{25}$, era justamente em Comte que Alain encontrava a motivação de sua filosofia política, tendo-lhe herdado o "princípio de Broussais" já comentado por Canguilhem desde seu já comentado memorial. Como acabamos de ver, esse princípio estabelecia uma continuidade - não havendo diferença qualitativa, portanto - entre os estados fisiológicos normal e patológico de um organismo. Aquilo que se manifestaria como diverso à ordem social seriam apenas diferenças quantitativas (no organismo ou na sociedade), às quais Broussais denominara como irritações ${ }^{26}$. Segundo essa perspectiva, Alain compreendia as revoluções e guerras como "irritações" do corpo social. Assim, sempre na esteira de Comte, o papel político dos cidadãos para Alain seria o de cuidar para sanar tais irritações, e o dos intelectuais seria o de auxiliar na condução do restabelecimento dessa ordem, pacífica e estável por natureza. Além disso, o pensamento francês do início do século XX vivia o auge do neokantismo, como bem descreveram Xavier Roth ${ }^{27}$ e Emiliano Sfara ${ }^{28}$ em duas teses recentes sobre Canguilhem. Assim, a essa herança da filosofia política comtiana deve-se acrescentar o fato de que, ao lado de Lagneau, Brunschvicq, Lachelier, Hamelin e Boutroux, Alain estava empenhado em construir uma "filosofia da atividade" fundada na concepção da unidade da experiência. Essa "filosofia da atividade" teria herdado os traços da Wertphilosophie da Escola de Baden, de Windelband e Rickert, que através desses autores se introduzia na França.

Segundo essa leitura recente, que se serve dos textos coligidos em suas Euvres complètes anteriores a Le normal et le pathologique, bem como dos arquivos disponibilizados in loco no CAPHÉS-ENS de suas notas de curso da época, o “jovem Canguilhem” teria realizado como que uma síntese entre o positivismo e a Wertphilosophie, na herança de seu primeiro mestre Alain. De fato, muitas são também as recorrências de Canguilhem à Wertphilosophie nos textos dessa época, assim como nos cursos que proferiu em liceus no mesmo período ${ }^{29}$. Se em 1926, em seu memorial, já se demonstrava a importância de Comte em ter sabido colocar a distinção moral entre fato e valor, numa intervenção nos Libres Propos, no ano seguinte, não era outro o posicionamento de Canguilhem: "o fato não tem valor por si mesmo" "30, escrevia. Conforme a herança do neokantismo, não havendo propriamente uma ordem primeira a ser intuída no próprio real ou na natureza, a tarefa da filosofia seria a de criar unidade lá onde ela não existe, tarefa cujas condições seriam incessantemente recolocadas pela experiência empírica e pelo contexto histórico contingente. Esta unidade, por sua vez, só poderia aparecer se a filosofia fosse compreendida enquanto uma axiologia, devendo haver uma hierarquia dos valores segundo a qual o valor moral é quem deveria guiar e coordenar a experiência e a ação em sua pluralidade.

\footnotetext{
25 BIANCO, "Pacifisme et théorie des passions : Alain et Canguilhem".

${ }^{26}$ Para um aprofundamento na compreensão desse autor, ver: BRAUNSTEIN, Broussais et le matérialisme: médecine et philosophie au XIXe siècle.

${ }^{27}$ ROTH, Georges Canguilhem et l'école française de l'activité. Em especial, toda a primeira parte dessa tese.

${ }^{28}$ SFARA, La philosophie de Georges Canguilhem à travers son enseignement, 1929-1971: examen du concept d'action.

${ }_{29}^{29}$ Para uma análise desse período em Canguilhem, ver também: SCHWARTZ, "Jeunesse d'un philosophe".

30 CANGUILHEM, Libres Propos, 20/04/1927, p. 167.
} 
Nas décadas de 1920-1930, era notável o papel que Alain exercia como "éveilleur"31 da geração dos jovens estudantes parisienses, mobilizando muitos deles - como Simone Weil, Michel e Jeanne Alexandre, além de Canguilhem - a engajarem-se num movimento, por vezes inflamado, contra a ameaça de um novo conflito mundial. Com efeito, por esses anos Canguilhem militava também por um programa pacifista, chegando a reagir com relutância aos argumentos que seu estimado colega Raymond $\operatorname{Aron}^{32}$ um dia desferiu contra os perigos do que denominou como o "pacifismo integral" de Alain. Foi no ano de 1933, quando o avanço do fascismo na Europa (Mussolini em 1922, Hitler em 1933, Franco em 1933) anunciava a iminência de que também se ganhasse a França, fosse pelo voto, fosse por um golpe de Estado. Raymond Aron questionava se essa postura pacifista não acabaria por levar a aceitar passivamente as "lições históricas" que estavam por vir, antevendo que muitos dos alainistas acabariam por aderir à Colaboração, como de fato ocorreu.

Mas se, num primeiro momento, Canguilhem reagiu negativamente aos argumentos do colega, a intensificação nos anos seguintes das ameaças fascistas seria decisiva para uma progressiva mudança de posição de nosso autor. Ele refletirá sobre o fato de que a opção pelo pacifismo não deveria ser medida em termos de um valor moral universalmente válido tal como o de uma Paz. A decisão por uma militância em favor da Paz - conceito vago deveria ser circunstanciada, como toda e qualquer ação. Antes que ele lesse em René Leriche - o autor de La philosophie de la chirurgie - que a saúde seria apenas "a vida no silêncio dos órgãos", Canguilhem refletiu sobre o fato de que a Paz também poderia não ser mais do que a vida social no silêncio das batalhas. Percebendo a falta de sentido histórico de que a filosofia pacifista de Alain parecia eivada, pois que não era sensível às diferenças políticas entre as condições que haviam levado à Primeira Guerra Mundial e estas que logo culminariam na Segunda, Canguilhem acabará por romper com o pacifismo irrestrito de Alain por volta de 1935-1936. Um dos marcos dessa ruptura foi a publicação anônima de um texto político Le fascisme et les paysans (1935), o qual resultava de uma pesquisa empírica. Depois disso, já em 1936, tendo deixado a redação do periódico alainista Libres Propos, Canguilhem assumirá o posto de professor em Toulouse e se engajará nos estudos de medicina. Será o momento de criação de uma filosofia que reformulará de modo já original a herança recebida de suas primeiras referências.

\section{Um ato filosófico de resistência ao fascismo}

Como informa Michele Cammelli33, responsável pela apresentação do texto Le fascisme et les paysans (1935) nas Euvres complètes de Canguilhem, na data da publicação dessa brochura era corrente na França pensar que, embora o fascismo atingisse predominantemente os países que haviam perdido a Primeira Guerra Mundial, também se deveria ficar alerta para a possibilidade de sua ascensão na França. Embora fosse dever combater-se o inimigo que vinha de fora, começavam a preocupar também as ideias fascistas

\footnotetext{
31 A expressão aparece na seguinte obra, que vale como uma muito bem documentada reconstrução histórica do microcosmo intelectual da geração à qual pertenceu Canguilhem: Cf. SIRINELLI, Génération intellectuelle: Khâgneux et normaliens dans l'entre deux-guerres.

32 Veja-se o debate entre Aron e Canguilhem, reproduzido em: ARON, Réflexions sur le pacifisme integral, p. 999-1005; e CANGUILHEM, Libres Propos: mars/1933, pp. 450-453.

${ }^{33}$ CAMMELLI, "Présentation de Le fascisme et les paysans", pp. 515-533.
} 
que passavam a ganhar força também dentro da França, representando um perigo real. Era sem dúvida o momento político mais turbulento em toda a Europa desde o fim do primeiro conflito mundial. Os operários urbanos, organizados em sindicatos, haviam se organizado numa força antifascista. No campo, a situação estava dividida, havendo um número crescente de pequenos e médios produtores rurais simpáticos ao fascismo. Surgiram organizações fascistas rurais, como o Parti agraire et paysan français (PAPF), fundado em 1928, ligado ao ideal romântico de autenticidade camponesa; o Front Paysan, anti-parlamentar e anti-democrático; além da Croix de feu e das Jeunesses patriotes. Os efeitos da crise de 1929 contribuíram ainda mais para aumentar a força dessas organizações.

Como reação a esse avanço, passaram a surgir, em contrapartida, organizações contrárias ao fascismo, o que se deu em várias frentes. Uma delas, o "Comité de Vigilance des Intellectuels Antifascistes" (CVIA), consistiu num órgão de intelectuais suprapartidário que buscava relacionar-se diretamente com os sindicatos, com a função de oferecer aos trabalhadores um laboratório de análises políticas na França, tentando produzir análises a respeito dos estratos sócio-econômicos mais expostos à propaganda fascista. Por influência de Camille Planet, com quem iria redigir o Traité de logique et de morale (1939), Canguilhem passou a integrar o CVIA, publicando anonimamente a brochura Le fascisme et les paysans (1935), seguida de uma enquete.

O objetivo do texto era alertar a militância antifascista a respeito das particularidades do mundo rural francês, que Canguilhem conhecia bem por dele provir. De nada adiantaria, diz Canguilhem, pregar aos camponeses que o fascismo seria uma força do capitalismo organizada para destruí-los; isso não iria fazer com que eles se mobilizassem contra o fascismo, sendo a quase-totalidade dos camponeses indiferente às organizações operárias, quando não lhes era hostil. Canguilhem invocava Marx (e com efeito esta é a época em que seu pensamento mais esteve próximo de $\left.\operatorname{Marx}^{34}\right)$, buscando auxílio para interpretar as consequências do período pós-Revolução até o início do século XX sobre a situação dos camponeses na França e para traçar o quadro geral sociológico sobre o qual analisará as motivações de sua adesão ao fascismo, buscando apresentar meios para tentar evitá-la. E é nesse texto também que Canguilhem aborda com certo fôlego, pela primeira vez, a transição da sociedade rural para a sociedade industrial em alguns de seus efeitos, algo que irá permanecer em suas diversas análises a respeito do taylorismo e da racionalização do trabalho, efeito do crescimento do controle da vida local por um poder central e totalitário: "dos campos às fábricas, das assembleias locais aos escritórios centrais. O individualismo rural é subordinado ao anonimato urbano, e a vida pessoal ao automatismo social" ${ }^{35}$. Contudo, Canguilhem recusa a análise do fascismo como um simples produto de um capitalismo em crise, preferindo defini-lo, como novamente nos elucida M. Cammelli, como "uma nova técnica de governo que visa a controlar de maneira 'totalitária' todos os aspectos da vida da

34 Cf. SCHWARTZ, "Jeunesse d'un philosophe”, p. 92n. Numa nota final de Les fascisme et les paysans, Canguilhem esclarece o que pensa a respeito do termo "socialismo": "Entende-se que não quisemos designar pela palavra socialismo, frequentemente empregada nesse estudo, a doutrina de tal partido político atual. Tomamos a palavra no sentido puramente teórico, filosófico se quisermos, de organização sistemática da economia, para e pelos trabalhadores, com vistas a uma abolição real da escravidão humana. Esta brochura não é um programa, mas a pesquisa de noções e de princípios para um programa possível" (CANGUILHEM, Le fascisme et les paysans, p. 572).

${ }_{35}$ CANGUILHEM, Le fascisme et les paysans, p. 545. 
população e a reduzi-la a uma obediência automática" ${ }^{36}$. E com o mesmo estilo ríspido com que havia se empenhado em muitas intervenções anteriores militando pela causa de Alain, agora Canguilhem começa a expressar ares de uma nova revolta: "A união de todos os camponeses, que sonho propriamente pastoral! Mas a paz do campo nunca existiu senão na imaginação dos poetas". ${ }^{37}$

Seu apelo é pela distinção das diferenças entre as categorias às quais pertenciam cada camponês, devendo-se individualizá-los a fim de compreendê-los, excluindo-se das propagandas a palavra de ordem "coletivismo". A organização coletiva, se ela deveria haver, deveria ocorrer por deliberação individual, e afirmando-o Canguilhem criticava o comunismo de Estado. Como nota outro comentador, desta vez D. Lecourt, neste texto Canguilhem "convida as organizações de esquerda a renunciar às simplificações conceituais sobre o 'mundo camponês' veiculadas pela vulgata marxista que triunfou na União Soviética para a maior tristeza dos camponeses" ${ }^{38}$. Dever-se-ia impedir que, por deliberação individual, os camponeses preferissem aderir, não aos trabalhadores industriais, mas aos proprietários que se proclamavam a favor da unidade do mundo. Para isso, Canguilhem tenta denunciar os interesses que estariam por trás do nacional-socialismo de Hitler, mostrando que não se tratava de defender os interesses dos pequenos produtores, mas sim os privilégios dos grandes proprietários, e buscava alertar para o que esse aparato militar escondia:

O que o camponês deve compreender é que a extensão em todos os países do aparelho militar, mal dissimulado sob uma linguagem de protestos pacíficos condicionais, é antes de tudo um fenômeno e uma manobra de política interior. Trata-se, primeiro, de criar um estado de espírito favorável à obediência automática, único meio de manter um regime quando ele não pode ser justificado; trata-se, em seguida, de assegurar ao Estado uma força repressiva fulminante contra as reações de revolta dos trabalhadores ou dos pequenos possuidores oprimidos. ${ }^{39}$

Em suma, Canguilhem argumentava que a pregação ao coletivismo no mundo rural só iria facilitar a sua união em torno dos partidos de direita e de extrema-direita. Isso porque os pequenos e médios produtores rurais compreendiam-se a si mesmos como produtores de seus próprios objetos de consumo, como independentes e orgulhosos dessa condição que os mantinha na base da produção econômica. Por fim, o camponês também via a si mesmo como subestimado pelas demais classes sociais, que o julgavam como inferior na escala do

\footnotetext{
${ }^{36}$ CAMMELLI, "Présentation de Le fascisme et les paysans", p. 527. O leitor familiarizado com as análises foucaultianas sobre a transição entre o poder disciplinar e o biopoder não deixará de notar aqui certa similaridade.

${ }^{37}$ CANGUILHEM, Le fascisme et les paysans, p. 547.

${ }^{38}$ LECOURT, Georges Canguilhem, p. 23.

39 CANGUILHEM, Le fascisme et les paysans, p. 565. Reparemos que a crítica à disciplina militar já aparecia em Canguilhem desde os anos 1920, como nota Braunstein: "Canguilhem não conheceu a guerra diretamente, mas ele fez seu serviço militar: ora, segundo ele, o exército já é a guerra. As "Notas militares" ou "Notas de um soldado", aparecidas entre 1927 e 1929, anônimas mas que podem sem nenhuma dúvida lhes ser atribuídas, descrevem bem a absurdez da vida militar, dessa 'prisão' que constitui para ele o exército. O exército degrada o homem (...) O exército se serve do homem como instrumento (tal como a psicologia fará dele). Sua crítica da guerra também refuta os argumentos biologistas (darwinismo social); e constitui, por fim, uma crítica da exploração capitalista” (BRAUNSTEIN, À la découverte d'un « Canguilhem perdu », pp. 107-9).
} 
progresso civilizatório. "A honra do campesinato está justamente no sentimento que ela tem de assegurar a junção entre a natureza e a sociedade" ${ }^{40}$. Por isso, o desentendimento entre o operário urbano e o pequeno e médio produtor rural começaria com o fato de que o operário se serviria do produto do camponês (alimentação) que, por sua vez, segundo o modelo capitalista de redução de custo pela livre concorrência, teria de ver seu produto desvalorizado em detrimento do produto do trabalho do operário urbano (que também deveria poder viver com baixo salário).

\section{Conclusão: a ruptura com o pacifismo}

Esse texto de Canguilhem, "Le fascisme et les paysans", marca sua primeira grande incursão numa matéria "estranha" à filosofia. Os resultados dessa incursão serão, em seguida, reordenados pela filosofia, segundo seu papel reflexivo, que avalia e reavalia de modo crítico o que se lhe vem do exterior. Essa ruptura com o pacifismo, que então se anunciava, levou a uma ruptura com relação aos demais pressupostos da filosofia de Alain, bem como com sua concepção da Eterna História e de uma natureza humana imutável em que esta última se sustenta. Num artigo de 1952, escrito no ano seguinte à morte de seu primeiro mestre, com quem contudo nunca perdera a amizade, Canguilhem fará uma revisão bastante elogiosa da filosofia estética de Alain, não poupando, porém, seu "pacifismo integral" e a opção de muitos de seus adeptos pela Colaboração. Embora Canguilhem enalteça o fato de Alain, assim como Bergson, ter atribuído uma originalidade ontológica à criação, é pela sua concepção neokantiana de natureza humana que Canguilhem recusará as consequências políticas de sua filosofa, as quais também se deixariam pressentir em sua filosofia estética, sendo o gênio a disposição inata do espírito pela qual a natureza daria suas regras à arte:

Por mais contraditório que pareça, [diz Canguilhem,] é um fato que essa fisiologia das belas-artes, que ele fez mais do que esboçar, não é uma ciência do movimento das formas ou das formas em movimento (o que deve ser uma fisiologia autenticamente fisiológica): é ainda uma morfologia estática. ${ }^{41}$

E ainda que o homem acrescentasse à natureza o trabalho (ideia hegeliana, mas que Alain teria desenvolvido antes de ter lido Hegel), não haveria um papel para a história em Alain: "Alain crê na natureza humana, na Eterna História” (Ibid., p. 428). É de Comte (a ordem comanda o progresso), e não de Hegel, que Alain se reclama. E é acima de tudo uma ideia platônica que proclama a primazia do ser sobre o devir. Tal concepção, como se viu, estava radicada na concepção humanista de progresso universal como desenvolvimento da ordem, tendo sido, por sua vez, herdada de Comte. Calcava-se, enfim, numa homologia essencial entre os estados de guerra e de paz, ou entre os estados normal e patológico ("princípio de Broussais"). E tendo sido reconhecidas todas as consequências dessa ruptura, também deverão ser observadas as suas "conservações de herança", bem como as suas consequências para as novas reformulações que passarão a ser entabuladas por Canguilhem.

${ }^{40}$ CANGUILHEM, Le fascisme et les paysans, p. 558.

${ }^{41}$ CANGUILHEM, "Réflexions sur la création artistique selon Alain", p. 428 


\section{Referências bibliográficas}

ALAIN (Émile Chartier). Mars ou la guerre jugée. Paris: Gallimard, 1921.

ARON, R. "Réflexions sur le pacifisme intégral". In: CANGUILHEM, G. CEuvres Complètes, vol. I: écrits philosophiques et politiques (1926-1939). Paris: Vrin, 2011, pp. 999-1005.

BIANCO, G. Pacifisme et théorie des passions: Alain et Canguilhem. IN: MURAT, M.; WORMS, F. Alain, littérature et philosophie mêlées. Paris: Éditions rue d'Ulm / Presses de l'École Normale Supérieure, 2012, pp. 129-150.

BRAUNSTEIN, J.-F. Broussais et le matérialisme: médecine et philosophie au XIXe siècle. Paris: Klincksieck, 1986.

Canguilhem avant Canguilhem. In: Revue d'bistoire des sciences, t. 53, n. 1 (jan-mar 2000), 2000, pp. 9-26.

La philosophie de la médecine d'Auguste Comte: vaches carnivores, Vierge Mère et morts vivants. Paris: PUF, 2008.

"À la découverte d'un "Canguilhem perdu »". In: CEuvres Complètes, vol. I: écrits philosophiques et politiques (1926-1939). Paris: Vrin, 2011, pp. 101-137.

CAMMELLI, M. "Présentation de Le fascisme et les paysans (1935)". In: CANGUILHEM, Georges. CEuvres complètes, tome I. Paris: Vrin, 2011, pp. 515-533.

CANGUILHEM, G. [1926] Théorie de l'ordre et du progrès chez. Comte. CAPHÉS: GC. 6.1. [notas de arquivo inéditas].

[1927] Libres Propos, 20/04/1927. In: Euvres Complètes, vol. I: écrits philosophiques et politiques, 1926-1939. Paris: Vrin, 2011, pp. 162-167.

[1933] Libres propos: março/1933: In: Cuvres Complètes, vol. I: écrits philosophiques et politiques, 1926-1939. Paris: Vrin, 2011, pp. 450-453

[1935] Le fascisme et les paysans. In: CEuvres Complètes, vol. I: écrits philosophiques et politiques, 1926-1939. Paris: Vrin, 2011, pp. 535-593.

[1943] Le normal et le pathologique [título original: Essai sur quelques problèmes concernant le normal et le pathologique]. $5^{\mathrm{a}}$ ed. Paris: PUF, 1984.

[1952] "Réflexions sur la création artistique selon Alain". In: Euvres Complètes, vol. IV : résistance, philosophie biologique et histoire des sciences (1940-1965). Paris: Vrin, 2015, pp. 415-435.

DELAPORTE, F. (ed.) [1994] A vital rationalist: selected writings from Georges Canguilhem. $2^{\mathrm{a}}$ ed. Tradução inglesa Arthur Goldhammer. Nova Iorque: Zone Books, 2000. 
LECOURT, D. Georges Canguilhem. Paris: PUF, 2008.

LEECH, J. W. [1965] Mecânica Analítica. Tradução de Carlos Campos de Oliveira. São Paulo: Edusp, 1971.

LIMOGES, C. [1994] "Critical bibliography”. In: DELAPORTE, F. (éd.) A vital rationalist: selected writings from Georges Canguilhem. $2^{\mathrm{a}}$ ed. Tradução inglesa Arthur Goldhammer. Nova Iorque: Zone Books, 2000, pp. 385-454.

ROTH, X. Georges Canguilhem et l'école française de l'activité [publicada posteriormente como Georges Canguilhem et l'unité de l'expérience. Paris: Vrin, 2013]. Tese de Doutorado. Université du Quebec, 2010.

SFARA, E. La philosophie de Georges Canguilhem à travers son enseignement, 1929-1971: examen du concept d'action. Thèse en philosophie. [publicada posteriormente como Georges Canguilhem inédit: Essai sur une philosophie de l'action. Paris: 1'Harmattan, 2018] Montpellier: Université Paul Valéry, 2015.

SCHWARTZ, Y. "Jeunesse d'un philosophe". In: CANGUILHEM, Georges. CEuvres complètes, vol. 1: écrits philosophiques et politiques (1926-1939). Paris: Vrin, 2011, pp. 71-99.

SIRINELLI, J.-F. Génération intellectuelle: Khâgneux et normaliens dans l'entre deux-guerres. Paris: Fayard, 1988. 